\title{
Techniques for Improving the Tissue Culture Efficiency of Purple Passion Fruit (Passiflora edulis)
}

\author{
Dongmei Huang ${ }^{1,2}$, Bin $\mathrm{Wu}^{1,2}$, Funing $\mathrm{Ma}^{1,2}$, Di Chen ${ }^{1}$, Yi Xu ${ }^{1,2}$ and Shun Song ${ }^{1,2^{*}}$ \\ ${ }^{1}$ Haikou Experimental Station, Chinese Academy of Tropical Agricultural Sciences, Key Laboratory of Genetic Improvement \\ of Bananas, Haikou, Hainan Province, 571101, China \\ ${ }^{2}$ Hainan Key Laboratory for Biosafety Monitoring and Molecular Breeding in Off-Season Reproduction Regions, Sanya, \\ Hainan Province, 572000, China
}

"For correspondence: songs@ catas.cn

Received 10 October 2020; Accepted 23 October 2020; Published 10 January 2021

\begin{abstract}
Purple passion fruit (Passiflora edulis Sims) has gained attention in Southern China, and its planting area has increased during the last several years. Through tissue culturing, virus-free plants are produced as maternal parents for seedling production. However, there are some difficulties that affect passion fruit tissue culture efficiency, including high contamination rates in explant disinfection, low shoot proliferation, yellow or albino leaves, slow growth, and time-consuming processes. In this work, the aforementioned problems were investigated, and disinfection was optimized. Results revealed that the repeat disinfection method $\left(0.1 \% \mathrm{HgCl}_{2}\right.$ for $15 \mathrm{~min}+0.1 \% \mathrm{HgCl}_{2}$ for $\left.12 \mathrm{~min}\right)$ with a 2-d interval was the most suitable disinfection treatment for young stem segments of purple passion fruit. The addition of silver thiosulfate (STS) improved proliferation efficiency. Moreover, additional 1X iron salt was added to the bud induction and rooting medium. The regenerated shoots had a better seedling state with healthier green leaves, roots were more easily induced and better developed and the chlorophyll contents were higher. Thus, more efficient tissue culturing of purple passion fruit was achieved. (C) 2021 Friends Science Publishers
\end{abstract}

Keywords: Passion fruit; Tissue culture efficiency; Disinfection; Silver thiosulfate; Iron salt

\section{Introduction}

Purple passion fruit (Passiflora edulis sims) is a vine crop that belongs to genus Passiflora and family Passifloreae. This was originated in South America and now widely cultivated in tropical and subtropical areas across the world (Ulmer and MacDougal 2004; Ortiz et al. 2012; Silva et al. 2014). Passion fruit is rich in a variety of flavors that is similar with pineapple, mango, guava, banana, and several other fruits (Fu et al. 2005; Janzantti and Monteiro 2017). The Chinese name for passion fruit is 'Bai Xiang Guo', which means fruit with 100 kinds of aroma. Passion fruit has got attention among consumers because of its unique flavor and nutritional elements. As a result, its planting area has expanded in Southern China as it is a short-term crop with high economic returns (Huang et al. 2019a). Two purple varieties, 'Tainong' and 'Zixiang', and a yellow variety, 'Golden yellow', are the main varieties cultivated in China. Virus-free seedlings are in high demand in China. Through tissue culturing, virus-free, true-to-type plants can be produced as planting materials for propagation (Prammanee et al. 2011). Tissue culturing is also an important tool for the ex situ conservation of Passiflora germplasm (Pacheco et al. 2016).
However, there are some difficulties that affect passion fruit tissue culture efficiency, including high contamination rates in explant disinfection, low bud proliferation, yellow and/or albino leaves, and slow growth. Due to its complex environment and the influence of diseases and insect pests, passion fruit stem tips and segments that were used as explants from the field contain endophytic bacteria. It is difficult to completely kill endophytic bacteria by ordinary disinfection methods, so it is necessary to improve the methods, which include repeat disinfection, mixed disinfectants with different agents, antibiotic pretreatment and the addition of antimicrobial agents in culture medium (Ji et al. 2011). The proliferation rate of passion fruit tissue culture is 1-3 per explant and the proliferation efficiency is low and time-consuming, lasting $\sim 6$ months or longer (Tuhaise et al. 2019), which is far lower than seedling cutting and grafting. Therefore, the application of tissue culture seedling production was of little significance and has not been applied in seedling production.

Node and primordia regions, which are essential for maintenance and growth during cell division, are the main sites of ethylene synthesis (Jha et al. 2007). Less elongation and radial swelling of the stem are primary indications of higher ethylene accumulation (Danish et al. 2019). Ethylene 
peaks occur during meristemoid differentiation in both $P$. edulis f. flavicarpa and P. cincinnata, resulting in delayed shoot induction (Dias et al. 2009). Therefore, it is necessary to optimize the shoot induction and proliferation system to obtain higher proliferation efficiency. Leaf edges of tissue culture shoots become yellow or albino at the shoot elongation and rooting culture stages, then gradually spread from the edge to the whole leaf. Afterward, the leaves fall off, which affects the growth of regenerated shoots and can causes the death of the whole shoot. A previous study showed that the micro-environment in a tissue culture bottle affects the success of plant tissue cultures, including the compositions and contents of inorganic salts, carbon sources, plant growth regulators, ethylene, and $\mathrm{CO}_{2}$ concentrations. Changes in these factors will lead to a lower $\mathrm{Fe}^{2+}$ content in the medium, imbalance in mineral nutrition, and slow shoot growth (Luo et al. 2012).

Thus, the aim of this study was to optimize the regeneration system, improve tissue culture efficiency, and enhance the rapid propagation of passion fruit using the improved explants disinfection method with the addition of ethylene inhibitors to reduce the ethylene contents in tissue culture bottles and trace elements in order to improve the seedling state of regeneration shoots.

\section{Materials and Methods}

\section{Plant materials}

Purple passion fruit var. 'Tainong' young stem segments with the shoot and stem tips were selected as tissue culture explants. Explants were surface-sterilized with $70 \%$ alcohol (v/v) for $30 \mathrm{~s}$, followed by disinfection for 12-15 min and rinsed 4 times with sterilized water. Murashige and Skoog (1962) salt and vitamins with $1.0 \mathrm{mg} / \mathrm{L} 6-\mathrm{BA}$ and $1.0 \mathrm{mg} / \mathrm{L}$ IAA were used as the basal medium for shoot induction, and half-strength MS medium with $2.0 \mathrm{mg} / \mathrm{L}$ IBA was used for rooting (Huang et al. 2019b). Cultures were kept in a growth chamber under $26 \pm 1^{\circ} \mathrm{C}$ with a $16 / 8 \mathrm{~h}$ light/dark photoperiod.

\section{Comparison of different disinfection methods}

Explants were soaked in commercial carbendazol for $5 \mathrm{~min}$, rinsed under running water for $2 \mathrm{~h}$, surface-sterilized with $70 \%$ alcohol (v/v) for $30 \mathrm{~s}$, disinfected for $12-15 \mathrm{~min}$, and rinsed 4 times with sterilized water. Four disinfection methods were used for comparison: two one-time disinfection methods (treatment 1: $0.1 \% \mathrm{HgCl}_{2}$ for $15 \mathrm{~min}$; treatment 2: $2 \% \mathrm{NaClO}$ for $15 \mathrm{~min}$ ) and two repeat disinfection methods with $2 \mathrm{~d}$ intervals (treatment 3: $0.1 \%$ $\mathrm{HgCl}_{2}$ for $15 \mathrm{~min}+0.1 \% \mathrm{HgCl}_{2}$ for $12 \mathrm{~min}$; treatment 4 : $0.1 \% \mathrm{HgCl}_{2}$ for $15 \mathrm{~min}+2 \% \mathrm{NaClO}$ for $12 \mathrm{~min}$ ). After 2 weeks, the contamination rates and uncontaminated survival rate were recorded. The contamination rate (\%) was calculated as follows:

$$
\begin{gathered}
\text { Contamination rate }=(\text { number of contaminated explants/total } \\
\text { number of explants }) \times 100 \% .
\end{gathered}
$$

The uncontaminated survival rate $(\%)$ was calculated as follows:

Uncontaminated survival rate $=$ (number of uncontaminated and surviving explants/total number of uncontaminated explants) $\times 100 \%$.

\section{Effect of silver thiosulfate (STS) for shoot induction}

To address the issue of low explant proliferation coefficients, $8 \mu \mathrm{mol} / \mathrm{L} \mathrm{STS}$ was added to the shoot induction medium; induction medium without STS was used as the control. Cultures were sub-cultured once a month and shoot growth was recorded after sub-culturing 3 times. To prepare $8 \mathrm{~m} M$ STS stored liquor, $16 \mathrm{~m} M$ Silver nitrate $\left(\mathrm{AgNO}_{3}\right)$ was added and slowly mixed with $128 \mathrm{~m} M$ sodium thiosulfate solution $\left(\mathrm{Na}_{2} \mathrm{~S}_{2} \mathrm{O}_{3}\right)$ in equal volumes. Then, the solution was filtered and sterilized with a $0.22 \mu \mathrm{M}$ membrane. The molar concentration $(\mathrm{mol} / \mathrm{L})$ of STS was equal to the molar concentration (mol/L) of $\mathrm{AgNO}_{3}$ and the final concentration of the culture medium was $8 \mu \mathrm{mol} / \mathrm{L}$. The solution was not suitable for storage, thus it was prepared and used in time.

\section{Effect of iron salt in the nutrient base for regenerated shoot growth}

Considering the phenomenon of leaf yellowing and albinism in the later stages of tissue culturing, the basal induction and rooting medium were supplemented with iron salt with a total of 3 treatments: no additional salt (control), additional $1 \mathrm{X}$ iron salt, and additional $2 \mathrm{X}$ iron salt. Cultures were subcultured once a month and shoot, leaf, and root growth were recorded after subculturing 3 times in the same medium. Leaf chlorophyll was extracted with an acetone: ethanol (1:1) mixture and measured with an ultraviolet spectrophotometer. Absorbance values were recorded at wavelengths of 645 and $663 \mathrm{~nm}$. Chlorophyll contents were calculated as follows (Yan et al. 2018):

$$
\begin{gathered}
\mathrm{Ca}=\left(12.72 \times \mathrm{A}_{663}-2.59 \times \mathrm{A}_{645}\right) \times \mathrm{v} /(1000 \times \mathrm{m}), \\
\mathrm{Cb}=\left(22.88 \times \mathrm{A}_{645}-4.67 \times \mathrm{A}_{663}\right) \times \mathrm{v} /(1000 \times \mathrm{m}), \\
\mathrm{Ca}+\mathrm{Cb}=\left(8.05 \times \mathrm{A}_{663}+20.29 \times \mathrm{A}_{645}\right) \times \mathrm{v} /(1000 \times \mathrm{m}),
\end{gathered}
$$

Where $\mathrm{Ca}$ represents the chlorophyll A content, $\mathrm{Cb}$ represents the chlorophyll $\mathrm{B}$ content, $\mathrm{Ca}+\mathrm{Cb}$ represents the total chlorophyll content, $\mathrm{v}$ represents the total filtrate volume $(\mathrm{mL})$, and $\mathrm{m}$ represents the leaf weight $(\mathrm{g})$.

\section{Results}

\section{Effects of different disinfectants and methods}

Results revealed that different disinfectants and methods exerted different effects. Treatment 2 had the highest contamination rates with more fungal contamination and a 


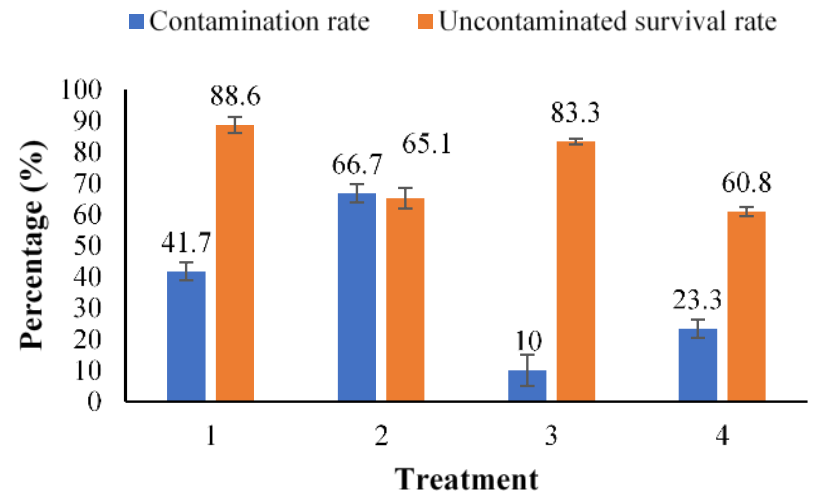

Fig. 1: Effects of different disinfection methods on purple passion fruit stem tips and segment (treatment $1: 0.1 \% \mathrm{HgCl}_{2}$ for $15 \mathrm{~min}$; treatment 2: $2 \% \mathrm{NaClO}$ for $15 \mathrm{~min}$; treatment 3: $0.1 \% \mathrm{HgCl}_{2}$ for 15 $\min +0.1 \% \mathrm{HgCl}_{2}$ for 12 min with a 2-d interval; treatment $4: 0.1 \%$ $\mathrm{HgCl}_{2}$ for $15 \mathrm{~min}+2 \% \mathrm{NaClO}$ for 12 min with a 2-d interval)

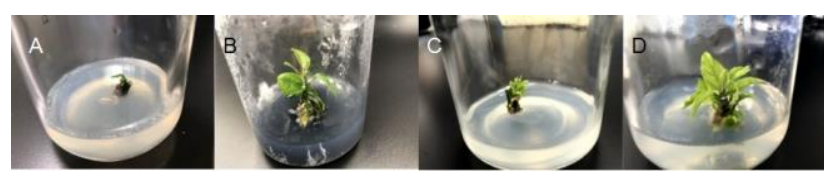

Fig. 2: Shoot induction in medium with and without silver thiosulfate (STS). A: Initial shoot growth in medium without STS; B: Multiple shoot induction in medium without STS; C: Initial shoot growth in medium with STS; D: Multiple shoot induction in medium with STS

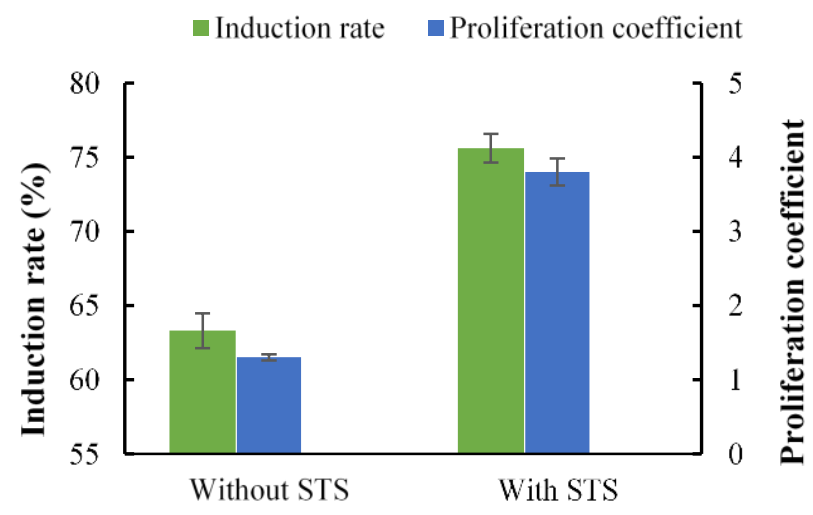

Treatment

Fig. 3: The shoot induction rates and proliferation coefficients of medium with and without silver thiosulfate (STS)

small amount of bacterial contamination, which occurred 2$3 \mathrm{~d}$ after disinfection. Treatment 1 had the second-highest contamination rates, which occurred 4-5 d after disinfection. The contamination rates of the repeat disinfection methods with a 2-d interval were lower than the one-time disinfection methods. In the repeat disinfection methods, the uncontaminated survival rate of the $\mathrm{HgCl}_{2}$ treatment was higher than the $\mathrm{NaClO}$ treatment, indicating that the former treatment exerted less damage to explants and was more conducive to their survival. These results indicate that the repeat disinfection method treatment 3 $\left(0.1 \% \mathrm{HgCl}_{2}\right.$ for $15 \mathrm{~min}+0.1 \% \mathrm{HgCl}_{2}$ for $\left.12 \mathrm{~min}\right)$ with a 2$\mathrm{d}$ interval was the best method for disinfecting purple passion fruit stem segment and tips (Fig. 1).

\section{Effects of STS on shoot induction}

Only a few adventitious shoots were induced in medium without STS after one month. Although new shoots were induced after several subcultures, their growth was slow, elongation was not obvious, leaves were shrunken and did not extend as far as in other treatments, and the newly induced shoots turned yellow and died gradually until only one main shoot remained, resulting in weak growth and a low proliferation rate. Shoot induction and growth were better in medium with STS and adventitious shoots were induced within 3 weeks. After 2 sub-culturing cycles, the proliferation efficiency reached 3-5 per explant. The main shoot and newly induced shoots grew well and elongated normally, leaves were normal and stretched, and the leaf area was larger than medium without STS. Therefore, the addition of STS to induction medium was beneficial for shoot induction, adventitious shoot elongation, and normal leaf growth (Fig. 2 and 3).

\section{Effects of iron salt on shoot growth and rooting}

In the 3 shoot and rooting induction medium treatments, results revealed that the controls had shoot induction but the leaves were yellowing, albino, and falling off with continuous growth, which eventually led to regeneration buds left on the trunk with weak growth vigor and cultures that died. Due to the lack of or yellow/albino leaves, plant growth potential was poor and rooting was difficult. The $2 \mathrm{X}$ iron salt treatment resulted in shoot induction, but the leaves had a yellow-green grid in color with leaf growth, exhibiting nutrient deficiency symptoms compared to healthy leaves; the leaves also fell off, indicating that the excessive iron salt concentration was not conducive to normal leaf growth. Regenerated shoots induced rooting in the rooting stage, but the root system was weak. The $1 \mathrm{X}$ iron salt treatment had better result than the other treatments in the shoot induction and rooting stages with healthy green leaves. In the rooting stage, roots were easily induced, the root system was developed, and plants were robust (Fig. 4). The leaf chlorophyll contents of the 3 treatments showed that the $1 \mathrm{X}$ iron salt treatment was the highest, followed by $2 \mathrm{X}$ iron salt, while the leaf chlorophyll content in the control was the lowest (Fig. 5).

\section{Discussion}

The most commonly used disinfectants are mercuric chloride $\left(\mathrm{HgCl}_{2}\right)$, sodium hypochlorite $(\mathrm{NaClO})$, and hydrogen peroxide $\left(\mathrm{H}_{2} \mathrm{O}_{2}\right)$. Among them, $\mathrm{NaClO}$ has the 


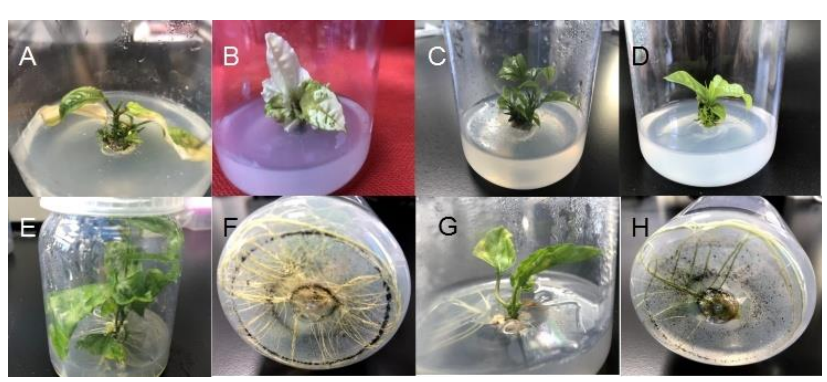

Fig. 4: Effects of iron salt on the growth and rooting of regenerated shoots (plants without additional iron salt exhibited obvious deficiency symptoms, including yellowing, abscission (A), and albinism (B). C: Plants with additional 1X iron salt showed robust regenerated shoot growth. D: Plants with additional $2 \mathrm{X}$ iron salt showed yellow-green grid colors on the leaves. E: Plants with additional $1 \mathrm{X}$ iron salt were robust and green. F: Plant roots with additional $1 \mathrm{X}$ iron salt were developed. G: Plant growth with $2 \mathrm{X}$ additional iron salt was weak with some yellow spots on the leaves. H: Plant root growth with additional $2 \mathrm{X}$ iron salt was weak

$$
\square \mathrm{Ca} \square \mathrm{Cb} \square \mathrm{Ca}+\mathrm{Cb}
$$

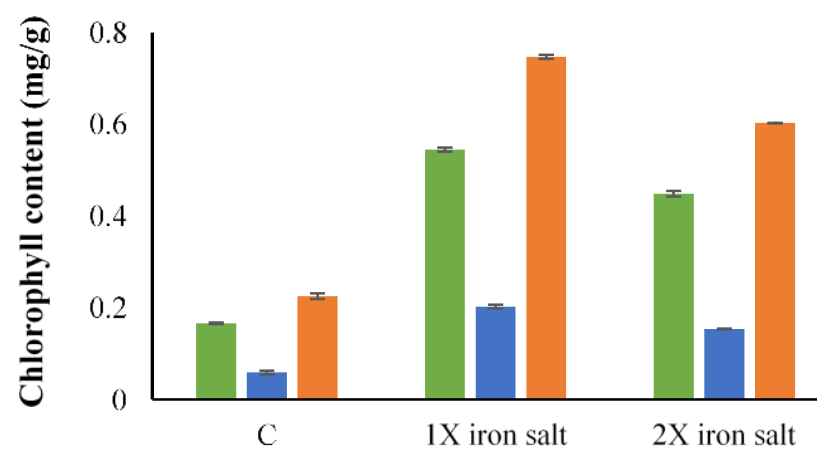

Fig. 5: Effects of iron salt on plant chlorophyll contents (Ca: chlorophyll a; $\mathrm{Cb}$ : chlorophyll $\mathrm{b}$; $\mathrm{Ca}+\mathrm{Cb}$ : total chlorophyll content; C: control)

smallest disinfection effect and its germicidal effect is worse than $\mathrm{HgCl}_{2}$. Generally, increasing the sterilization time improves its germicidal efficacy. However, if the time is too long, it will lead to dehydration of explants, which is not conducive for survival. $\mathrm{HgCl}_{2}$ has a better disinfection effect, but high toxicity and is difficult to remove (Lin et al. 2013). Thus, the selection of disinfectants and treatment time need to be optimized. The repeat disinfection method has been applied in the tissue culture disinfection of grapefruit (Liu et al. 2017), soybean (Shan et al. 2013), and other plants. After sterilization with $\mathrm{NaClO}$ or $\mathrm{HgCl}_{2}$, although most of the bacteria and fungi are killed, some spores remain due to their strong resistance to the disinfectants. After cultivation $(\sim 2 \mathrm{~d})$, some spores germinate under a suitable temperature and humidity, but their resistance decreased after germination. Thus, they are more easily killed in second sterilization treatments, even if the disinfection time in the second sterilization is reduced compared to the first. This method can reduce contamination rates and greatly improve the effects of disinfection.

Auxin and cytokinin contents can promote ethylene production in plant cells and tissues in in vitro cultures. Ethylene peaks occur during the meristemoid differentiation period and result in delayed shoot induction (Dias et al. 2009). The higher ethylene production rate of $P$. edulis may limit its morphogenetic potential (Ludford 1995), causing the leaves of tissue culture seedlings to become smaller and even cause plantlets to die (Guo et al. 2004). To avoid the negative effects of ethylene, a porous membrane cap or the addition of ethylene antagonists in culture medium can alleviate these effects (Luo et al. 2012). Silver nitrate $\left(\mathrm{AgNO}_{3}\right)$ and STS are ethylene antagonists. Some studies showed that $\mathrm{AgNO}_{3}$ can improve the shoot proliferation coefficient and rooting effects of Picea asperata cotyledon nodes (Venkatachalam et al. 2017), as well as shoot growth potential, which is better when $\mathrm{AgNO}_{3}$ is added to the induction medium of Passiflora spp. (Trevisan and Mendes 2005; Pinto et al. 2010). Compared to $\mathrm{AgNO}_{3}$, the silver ions in STS are more stable, easier to move in the plant vascular system, and have lower toxicity in plants; therefore, it is more suitable as an additive in plant tissue cultures (Ying and Chen 1990). Faria and Segura (1997) found that STS significantly promoted shoot induction and delayed explant senescence in P. edulis f. flavicarpa leaf tissue cultures. The addition of STS to potato tissue cultures also promoted plant growth, reduced the variation rate (Sarkar et al. 1999), and significantly increased the stem height, leaf area, and chlorophyll content of plantlet tissue cultures (Yuan et al. 2007). Generally, STS has a lower molar ratio than $\mathrm{AgNO}_{3}$ and is more stable (Ying and Li 1992). In this study, STS was prepared with a molar ratio of 1:8 (sodium thiosulfate: $\mathrm{AgNO}_{3}$ ) and the addition of STS to the medium was conducive for shoot induction, adventitious shoot elongation, and leaf growth. This study is the first to report on the tissue culture of purple passion fruit and the findings were consistent with previous studies on other species.

Iron salt is an important component of the basic medium for plant tissue culturing, which has a certain effect on plant tissue cultures and rapid propagation. Leaf chlorophyll a of photosystem II is the major source of fluorescence in green plants (Yang et al. 2018). In a previous experiment, purple passion fruit regenerated shoots were induced by MS basal medium and leaves were albino with abscissions, which affected shoot growth. $P$. edulis $\mathrm{f}$. flavicarpa plantlets in MS medium showed visual symptoms of mineral deficiency (chlorosis) and reduced growth, as well as symptoms of $\mathrm{Fe}, \mathrm{Ca}$, and $\mathrm{Mg}$ deficiency, while plantlets grown in adjusted medium, MSM, exhibited increased concentrations of $\mathrm{P}, \mathrm{Ca}, \mathrm{Mg}, \mathrm{S}, \mathrm{Fe}, \mathrm{Mn}, \mathrm{Cu}, \mathrm{Na}$, and EDTA, had green leaves, and were more elongated (Monteiro et al. 2000). Leaf cells from plants deficient in Fe had poorly developed palisade parenchyma with reductions in chloroplast numbers. Medium with high iron content 
improved these conditions. In a previous study, the survival rate of the primary culture of blueberry was improved by doubling the amount of iron in the medium (Liu et al. 2007), but in high-bush blueberry, high concentrations of iron salt inhibited proliferation and the chlorophyll contents of clump branches (Jiang and Yu 2009). In contrast, excessively high concentrations of iron salts tended to form a precipitation of iron phosphate, which affected the absorption of iron elements in plants and caused the loss of leaf greenness (Dalton et al. 1983; Hangarter and Stasinopoulos 1991). In our study, additional 1X iron salt in the shoot induction and rooting medium promoted leaf greenness and robust plantlet growth. Additionally, the chlorophyll content was higher compared with other treatments, which was consistent with previous studies. Thus, increased iron salt use should be moderated as excessive concentrations of iron salt are not conducive to plant growth and could cause nutritional imbalances.

\section{Conclusion}

The repeat disinfection method with a $2 \mathrm{~d}$ interval reduced contamination rates and enhanced the uncontaminated survival rate. The ethylene inhibitor STS was added to shoot induction medium and increased shoot differentiation and propagation efficiency. Moreover, additional $1 \mathrm{X}$ iron salt was added to the shoot induction and rooting medium, which promoted regenerated shoot growth, increased chlorophyll contents, improved leaf morphology, and promoted root formation and growth. Thus, the propagation efficiency of purple passion fruit tissue culture was improved.

\section{Acknowledgments}

This work was supported by the Key Research and Development Project of Hainan province (No. ZDYF2019090), Central Public-Interest Scientific Institution Basal Research Fund for Chinese Academy of Tropical Agricultural Sciences (No. 1630092020002), Guizhou Science and Technology Project No. 4005 (2019), and Guizhou Congjiang Zhenzun Industrial Co., Ltd.

\section{Author Contributions}

DH and SS planned and conducted the experiments. FM and $\mathrm{BW}$ interpreted the results. DC and YX analyzed the data.

\section{References}

Dalton CC, K Iqbal, DA Turner (1983). Iron phosphate precipitation in Murashige and Skoog media. Physiol Plantarum 57:472-476

Danish S, M Zafar-Ul-Hye, M Hussain, M Shaaban, A Núñez-Delgado, S Hussain, MF Qayyum (2019). Rhizobacteria with ACC-deaminase Activity Improve Nutrient Uptake, Chlorophyll Contents and Early Seedling Growth of Wheat under PEG- induced Drought Stress. Int J Agric Biol 21:1212-1220
Dias LLC, C Santa-Catarina, DM Ribeiro, RS Barros, EIS Floh, WC Otoni (2009). Ethylene and polyamine production patterns during in vitro shoot organogenesis of two passion fruit species as affected by polyamines and their inhibitor. Plant Cell Tiss Org Cult 99:199-208

Faria JLC, J Segura (1997). In vitro control of adventitious bud differentiation by inorganic medium components and silver thiosulfate in explants of Passiflora edulis f. flavicarpa. In Vitro Cell Dev Biol - Plant 33:209-212

Fu L, X Kang, T Liu (2005). Nutritional health value and pollution-free cultivation techniques of passion fruit. Hebei Fruits 33:35

Guo H, M Zhao, Y Li, J Liang, H Li, X Chen (2004). Application and prospects of $\mathrm{CO}_{2}$ in tissue culture. Acta Agric Nucl Sin 18:368-371

Hangarter RP, TC Stasinopoulos (1991). Effect of Fe-catalyzed photooxidation of EDTA on root growth in plant culture media. Plant Physiol 96:843-847

Huang D, Y Xu, B Wu, F Ma, S Song (2019a). Comparative analysis of basic quality of passion fruits (Passiflora edulis Sims) in Guangxi, Guizhou and Fujian, China. Bangl J Bot 48:901-906

Huang D, B Wu, F Ma, D Chen, S Song (2019b). Effects of different disinfectants and hormones on stem tissue culture of yellow passion fruit. Chin J Trop Agric 39:16-20

Janzantti NS, M Monteiro (2017). HS-GC-MS-O analysis and sensory acceptance of passion fruit during maturation. J Food Sci Technol 8:2594-2601

Jha AK, LS Dahleen, JC Suttle (2007). Ethylene influences green plant regeneration from barley callus. Plant Cell Rep 26:285-290

Ji C, L Jiao, W Liu, JH Zhao, RS Peng, ZS Yu, ZW Han, X Jin (2011). Reasons and prevention measures for the emergence of contamination in plant tissue culture. Liaon For Sci Technol 37:43-47

Jiang Y, H Yu (2009). Effect of Fe on in vitro shoot proliferation of promising southern high-bush blueberry selection. J Jilin Agric Univ 31:69-71

Lin F, J Li, S Chang, F Tang, B Wang (2013). The preliminary study in disinfection method of explants of Dalbergia odofifera in tissue culture. Genom Appl Biol 32:522-525

Liu Y, W Ye, Y Wang, H Liu, L Wang (2017). Disinfection and browning prevention for mature explant of grapefruit. North Hortic 7:131-135

Liu J, X Wu, X Liu, L Yang, Z Zhang, J Tao (2007). Tissue culture and in vitro micropropagation of blueberry. Jiangsu Agric Sci 35:101-103

Ludford PM (1995). Postharvest hormone changes in vegetables and fruit. In: Plant Hormones, Physiology, Biochemistry and Molecular Biology, pp:725-750. Davies PJ (Ed.). Kluwer Academic Publishers, Dordrecht, Netherlands

Luo X, X Jin, Z Wang, X Liu (2012). Effects of tissue culture microenvironment on regeneration plantlet growth. Nonwood For Res 30:147-150

Monteiro ACBA, EN Higashi, AN Gonçalves, APM Rodriguez (2000). A novel approach for the definition of the inorganic medium components for micropropagation of yellow passionfruit (Passiflora edulis Sims. f. flavicarpa Deg.). In Vitro Cell Dev Biol - Plant 36:527-531

Murashige T, F Skoog (1962). A revised medium for rapid growth and bioassays with tobacco tissue cultures. Physiol Plantarum 15:473-497

Ortiz DC, A Bohórquez, MC Duque, J Tohme, D Cuellar, TM Vasquez (2012). Evaluating purple passion fruit (Passiflora edulis Sims f. edulis) genetic variability in individuals from commercial plantations in Colombia. Genet Resour Crop Evol 59:1089-1099

Pacheco G, MJ Simão, MG Vianna, RO Garcia, MLC Vieira, E Mansur (2016). In vitro conservation of Passiflora-A review. Sci Hortic 211:305-311

Pinto APC, ACBA Monteiro-Hara, LCL Stipp, BMJ Mendes (2010). In vitro organogenesis of Passiflora alata. In Vitro Cell Dev Biol Plant 46:28-33

Prammanee S, S Thumjamras, P Chiemsombat, N Pipattanawong (2011) Efficient shoot regeneration from direct apical meristem tissue to produce virus-free purple passion fruit plants. Crop Prot 30:1425-1429 
Sarkar D, SK Kaushik, PS Naik (1999). Minimal growth conservation of potato microplants: Silver thiosulfate reduces ethylene-induced growth abnormalities during prolonged storage in vitro. Plant Cell Rep 18:897-903

Shan Z, F Han, X Zhang, A Sha, H Chen, L Chen, C Zhang, S Chen, X Zhou (2013). The application of double-disinfection method in preparation of soybean sterile seedling. Acta Agric Bor-Sin 28:275-277

Silva CBMC, ON Jesus, ESL Santos, RX Corrêa, AP Souza (2014). Genetic breeding and diversity of the genus passiflora: Progress and perspectives in molecular and genetic studies. Intl $\mathrm{J} \mathrm{Mol} \mathrm{Sci}$ $15: 14122-14152$

Trevisan F, BMJ Mendes (2005). Optimization of in vitro organogenesis in passion fruit (Passiflora edulis f. flavicarpa). Sci Agric 62:346-350

Tuhaise S, JL Nakavuma, J Adriko, K Ssekatawa, A Kiggundu (2019). In vitro regeneration of Ugandan passion fruit cultivars from leaf discs. BMC Res Notes 12; Article 425

Ulmer T, JM MacDougal (2004). Passiflora: Passionflowers of the World, pp:68-72. Timber Press, Portland, USA
Venkatachalam P, U Jinu, M Gomathi, D Mahendran, N Ahmad, N Geetha, SV Sahi (2017). Role of silver nitrate in plant regeneration from cotyledonary nodal segment explants of Prosopis cineraria (L.) Druce.: A recalcitrant medicinal leguminous tree. Biocatal Agric Biotechnol 12:286-291

Yan Z, J Nie, Y Cheng, D Guan, Z Li (2018). Determination of chlorophyll content in fruits, vegetables and their products. Chin Fruits 42:59-62

Yang Y, J Zhang, L Chen, A Ji, H Zhao, P Guo (2018). Effects of fertilizer levels and plant density on chlorophyll contents, its fluorescence and grain yield of Setaria italica. Intl J Agric Biol 20:737-744

Ying Z, S Li (1992). Stability of silver thiosulphate complex in MS medium and induction of maleness in Langenria siceraria. Bull Sci Techno $8: 42-45$

Ying Z, K Chen (1990). Physiological effects of ethylene antagonist-silver thiosulfate. Plant Physiol Commun 26:63-64

Yuan H, L Jin, S Huang, K Xie, Y Li, D Qu (2007). Effects of silver thiosulfate on the growth and antioxidative enzymes activities in tube seedling of potato under aeration and airtight conditions. Plant Physiol Commun 43:1082-1084 